\title{
Promoção ou prevenção? Análise das estratégias de comunicação do Ministério da Saúde no Brasil de 2006 a 2013
}

\author{
Promotion or prevention? Analysis of the communication strategies \\ carried out by Brazilian Health Ministry from 2006 to 2013
}

\section{Promoción o prevención? Análisis de las estratégias de comunicación del Ministerio de la Salud brasileño desde 2006 hasta 2013}

Wagner Robson Manso de Vasconcelos | wrmvasconcelos@gmail.com

Universidade de Brasília, Faculdade de Ciências da Saúde, Programa de pós-graduação em Ciências da Saúde. Brasília, DF, Brasil.

Fundação Oswaldo Cruz, Diretoria Regional de Brasília, Assessoria de Comunicação Social. Brasília, DF, Brasil.

Mariella Silva de Oliveira-Costa | mariellajornalista@gmail.com

Universidade de Brasília, Faculdade de Ciências da Saúde, Programa de pós-graduação em Ciências da Saúde. Brasília, DF, Brasil.

Fundação Oswaldo Cruz, Instituto de Comunicação e Informação Científica e Tecnológica em Saúde , Laboratório de Pesquisa em Comunicação e Saúde. Rio de Janeiro, RJ, Brasil.

Ana Valéria Machado Mendonça | valeriamendonca@gmail.com

Universidade de Brasília, Faculdade de Ciências da Saúde, Programa de pós-graduação em Ciências da Saúde. Brasília, DF, Brasil.

\section{Resumo}

Este artigo tem como objetivo analisar se as estratégias de comunicação do Ministério da Saúde brasileiro estão voltadas para a promoção da saúde ou orientadas para a prevenção de doenças. Para isso, foi realizada uma pesquisa qualitativa, baseada nas campanhas por ele promovidas, de 2006 a 2013, que dialogam com a Política Nacional de Promoção da Saúde, a saber: promoção de atividade física; promoção de hábitos saudáveis de alimentação e vida; combate ao tabagismo; controle do uso abusivo de bebida alcoólica e cuidados especiais voltados ao processo de envelhecimento. Com o foco em três categorias "direcionamento", "alvo" e "abordagem" - foram analisadas 14 campanhas, de modo a verificar se têm relação direta com a promoção da saúde. Constatou-se que, dessas, apenas três têm a promoção da saúde como alvo e direcionamento, mas as características da abordagem das demais não estão relacionadas com esse objetivo. Assim, concluiu-se que a comunicação das campanhas no período analisado esteve mais vinculada à prevenção de doenças do que à promoção da saúde.

Palavras-chave: Comunicação em saúde; promoção da saúde; campanhas promovidas pelo Ministério da Saúde brasileiro; meios de comunicação de massa; publicidade. 


\begin{abstract}
This article aims to analyse if the communication strategies carried out by Brazilian Health Ministry intend stimulating health promotion or diseases prevention. It is based on a qualitative research about the campaigns from 2006 to 2013 promoted by Health Ministry regarding the Política Nacional de Promoção da Saúde (Health Promotion National Policy), such as: physical activities; healthy eating and ways of life; stop smoking; alcoholic beverage use control, and special cares for aging process. The analysis has focused on three categories - "direction", "target" and "approach" - in order to verify if the campaigns have directly to do with health promotion. We observed that from 14 campaigns promoted, only three have target and direction related to health promotion; the approach of the other campaigns cannot be characterized as connected to it. We have come to the conclusion that the communication of the campaigns promoted by Brazilian Health Ministry, during the period analyzed, were rather linked to diseases prevention than to health promotion.
\end{abstract}

Keywords: Health communication; health promotion; campaigns promoted by Brazilian Health Ministry; mass media; publicity.

\title{
Resumen
}

Este artículo tiene el objetivo de analizar si las estrategias de comunicación del Ministerio de Salud brasileño se centran en la promoción de la salud o en la prevención de las enfermedades. Él está basado en una investigación cualitativa acerca de las campañas promovidas por aquel Ministerio, desde 2006 hasta 2013, relacionadas con los temas de la Política Nacional de Promoção da Saúde (Política Nacional de Promoción de la Salud): la promoción del ejercicio físico, la promoción de la alimentación y hábitos de vida saludables, contra el tabaquismo, el control del abuso de alcohol, y cuidados específicos destinados al proceso de envejecimiento. Enfocando el tema desde el punto de vista de las categorías direcionamento, alvo y abordaje, fueran analizadas 14 campañas para verificar si ellas tienen relación directa con la promoción de la salud. Se ha constatado que solamente tres tienen la promoción de la salud como alvo y direcionamento, y el abordaje de las otras no puede ser caracterizada así. La conclusión es que las campañas de comunicación del Ministerio de Salud brasileño en el período analizado han estado más vinculadas a la prevención de las enfermedades do que a la promoción de la salud.

Palabras clave: Comunicación en salud; promoción de la salud; campañas promovidas por el Ministerio de Salud brasileño; medios de comunicación de masas; publicidad.

INFORMAÇÕES DO ARTIGO

Contribuição dos autores:

Concepção e desenho do estudo - Wagner Vasconcelos

Aquisição, análise ou interpretação dos dados - Wagner Vasconcelos e Mariella Silva de Oliveira-Costa

Redação do manuscrito - Wagner Vasconcelos e Mariella Silva de Oliveira-Costa

Revisão crítica do conteúdo intelectual - Wagner Vasconcelos e Ana Valéria Machado Mendonça

Declaração de conflito de interesses: Não há.

Fontes de financiamentos: Não há.

Considerações éticas: $O$ artigo refere-se à análise de dados e informações disponíveis em meios públicos e abertos, não sendo realizadas entrevistas ou quaisquer outros tipos de intervenções diretas ou indiretas com seres humanos. Histórico do artigo: Submetido: 01.set.2015 | Aceito: 28.abr.2016| Publicado: 30.jun.2016.

Licença CC BY-NC atribuição não comercial. Com essa licença é permitido acessar, baixar (download), copiar, imprimir, compartilhar, reutilizar e distribuir os artigos, desde que para uso não comercial e com a citação da fonte, conferindo os devidos créditos de autoria e menção à Reciis. Nesses casos, nenhuma permissão é necessária por parte dos autores ou dos editores. 


\section{Introdução}

As discussões acerca do tema promoção da saúde vêm se pautando, especialmente a partir da década de 1980 - quando foi realizada a I Conferência Internacional sobre Promoção da Saúde ${ }^{1}$, pelo refinamento desse conceito e, particularmente, pela sua diferenciação de proposições próximas, mas não necessariamente iguais, como a prevenção de doenças.

No cotidiano e no imaginário popular, os conceitos de promoção e prevenção são comumente confundidos ou, então, erroneamente definidos como sinônimos. As razões para isso certamente são diversas e derivam de inúmeras questões, das epistemológicas às linguísticas e culturais. Buss ${ }^{2}$ atribui tal confusão, em parte, à ênfase dada em modificações de comportamento individual e "do foco quase exclusivo na redução dos fatores de riscos para determinadas doenças, vigentes em certos programas intitulados de promoção da saúde”. Obviamente se reconhece a importãncia da abordagem médica para a saúde da população, mas é preciso considerar fatores políticos e sociais para atingir as causas de doenças ${ }^{3}$. Czeresnia ${ }^{4}$, por sua vez, observa que as dificuldades na operacionalização dos projetos de promoção da saúde não diferem daquelas das estratégias de prevenção.

Este artigo, porém, não visa elucidar raízes de tais desentendimentos, tendo em vista que há, na literatura, extensos debates. O que se busca é investigar as relações entre a comunicação e a promoção da saúde, partindo do pressuposto de que o êxito desta não pode prescindir de um bom diálogo com aquela. E, entre essas relações, o esforço maior será voltado para avaliar se a comunicação que se processa no campo da saúde pública está, de fato, voltada para a promoção da saúde.

Desde que assumiu um papel de destaque no universo da saúde pública, a promoção da saúde tem inspirado discursos de gestores nos mais diversos campos, inclusive no da comunicação, tão estratégico para o setor por permitir não só a difusão de distintas informações sobre saúde como também processos comunicacionais alinhados, sobretudo, às diretrizes de participação social na definição das políticas públicas.

No Brasil, a promoção da saúde teve impulso na última década, especialmente após o lançamento da Política Nacional de Promoção da Saúde (PNPS) em 2006, que objetiva promover a qualidade de vida e reduzir a vulnerabilidade e os riscos da saúde relacionados aos seus determinantes e condicionantes - modos de viver, condições de trabalho, habitação, ambiente, educação, lazer, cultura, acesso a bens e serviços essenciais. O documento apresenta suas diretrizes e as atribuições das três esferas de governo, além dos principais eixos temáticos e avança, especialmente, no que diz respeito à integralidade das ações e sujeitos, tomando por base a complexidade dos conceitos de saúde, além de apresentar a necessidade de divulgação, sensibilização e mobilização para a promoção da saúde e definir ações singulares para temas específicos. A política define ações específicas para: alimentação saudável; prática corporal e atividade física; prevenção e controle do tabagismo; redução da morbimortalidade em decorrência do uso abusivo do álcool e de outras drogas; redução da morbimortalidade por acidentes de trânsito; prevenção da violência e estímulo à cultura da paz; e promoção do desenvolvimento sustentável ${ }^{5}$.

\section{Debatendo conceitos}

Mas será que há efetiva aplicação do conceito de promoção da saúde nas estratégias e ações de comunicação no Brasil? Alguns sinais da realidade podem indicar que ainda persiste na comunicação uma certa confusão conceitual, que gera uma comunicação muito mais 'preventiva' do que promotora de saúde. As campanhas de saúde veiculadas no Brasil talvez privilegiem anúncios informativos para prevenir o adoecimento da população, seja por meio de sua adesão a campanhas de vacinação (gripe e paralisia infantil, por exemplo), seja pela adoção de práticas de cuidados ambientais que minimizem as condições de proliferação de determinadas enfermidades (dengue, por exemplo). 
Porém, é importante observar que as prováveis confusões entre prevenção e promoção da saúde presentes na comunicação são reflexo da imprecisão conceitual que ainda persiste quanto ao termo 'promoção da saúde'. Portanto, cabe aqui breve revisão de literatura que permita um delineamento conceitual a partir do qual será possível analisar a comunicação que se processa perante o tema 'promoção da saúde'.

A relação da comunicação com a saúde, ainda que não apenas com a promoção da saúde, não é novidade. Talvez venha sendo considerada e explorada com maior ênfase mais recentemente, mas a sua vinculação é antiga. A importância da interface entre a comunicação e a saúde está, por exemplo, em seu papel na participação e no controle social, pois ambos se dão por meio de processos comunicacionais; logo, a participação dos sujeitos políticos na vida social vale-se do acesso às informações em saúde ${ }^{6}$.

No Brasil, isso pode ser verificado a partir da promulgação da Constituição Federal de 1988. Ao definir, em seu artigo 196, que "a saúde é direito de todos e dever do Estado", a Carta Magna estabelece que, embora a percepção sobre a definição e execução das políticas públicas indique o Poder Público como agente principal dessas ações, a participação popular nesses processos deve ser considerada. Isso porque as políticas públicas se dão a partir das relações e formas de interação entre governo, governantes e cidadãos ${ }^{7}$. A efetiva compreensão, assimilação e aceitação das políticas públicas dá-se pela visibilidade que alcançam e por sua conversão em saberes correspondentes e sintonizados com aqueles das populações que pretendem atingir. Logo, é indissociável sua relação com a comunicação que, na verdade, é um dos fatores determinantes do sucesso de uma dada política pública ${ }^{8}$.

A comunicação dos temas relacionados à promoção da saúde auxilia, portanto, as pessoas a terem acesso a eles, pois os trazem para o espaço público (ou esfera pública); espaço social destinado ao debate coletivo, segundo Habermas, sendo essencialmente um espaço comunicacional, a partir da prática de comunicação entre os cidadãos em torno de temas de interesse público9.

O papel da comunicação no universo da saúde pode, porém, ser estabelecido em grande medida por um viés operacional ou propagandístico (ou ainda, para usar um neologismo, 'campanhístico'). A produção de materiais de divulgação, as ações de assessoria de imprensa ou as campanhas publicitárias de cunho preventivo são as suas maiores marcas, uma vez que a comunicação configurou-se como parceira do público na prevenção dos males que possam afetar a sociedade ${ }^{10}$. É importante compreender a comunicação a partir de uma perspectiva transdisciplinar, dada a complexidade entre seu campo e o campo da saúde, buscando novas possibilidades de se olhar para o cotidiano empírico entre esses campos de saber. Para Edgar Morin, só a transdiciplinaridade conjuga os saberes e faz com que abordagens diferentes sejam colocadas em conjunto em prol de uma mesma finalidade, enquanto a interdisciplinaridade apenas juntaria disciplinas diferentes. Não se trata aqui, portanto, de apenas justapor elementos, mas de ligar os sentidos da comunicação e da saúde, de maneira complexa. "É preciso aceitar a aventura do pensamento complexo, pois o pensamento complexo nos dá instrumentos para ligar os conhecimentos" ${ }^{\prime 1}$. A comunicação se encontra com a saúde em várias dimensões, tanto acadêmicas (na criação de modelos teóricos e de alternativas para subsidiar a política de saúde) quanto práticas (técnicas para acesso às informações, diálogos entre os prestadores de serviços de saúde e a população etc.). A comunicação traz a saúde como objeto para produção do discurso (nos jornais, nas campanhas) e a saúde usa o saber comunicacional como ferramenta para prevenção e promoção ${ }^{12}$, mas não só; é importante salientar que a relação entre comunicação e saúde é complexa e tem nuances para além do aspecto instrumental entre um campo e outro. A interface entre a comunicação e a saúde é equivalente e complementar, cada campo com suas especificidades, ou seja, "discursividade, historicidade, agendas, lutas, agentes. Equivalência, porque são campos autônomos; complementaridade porque, uma vez conectados, um passa a ser condição de existência do outro. ${ }^{\text {"13 }}$

Portanto, para a promoção da saúde, a interface entre a comunicação e a saúde deve assegurar trocas de informações e não só a simples transmissão linear ${ }^{14}$. Há que se considerar, ainda, a comunicação envolvida nos processos educacionais e, mais especialmente, aquela que colabora com a formulação das políticas 
públicas. Este estudo demonstra, então, o papel estratégico da comunicação para a promoção da saúde, especialmente naquilo que se refere às ações comunicacionais das campanhas do Ministério da Saúde no Brasil. Cabe, portanto, explicitar de que promoção da saúde se trata aqui.

Desde a I Conferência Internacional sobre Promoção da Saúde, realizada em Ottawa, Canadá, em 1986, a expressão promoção da saúde tem-se tornado cada vez mais recorrente no universo da saúde pública. Diversas estratégias e campanhas de saúde enfatizam o termo, mas, ao mesmo tempo, lhe dão sentidos ambíguos. A compreensão do sentido mais apropriado passa pelo entendimento do contexto em que ele surgiu.

Quatro décadas antes dessa conferência, o termo promoção da saúde foi apresentado por Sigerist ${ }^{15}$ ao se referir às quatro tarefas essenciais da medicina: promoção da saúde, prevenção de doenças, recuperação dos enfermos e reabilitação. $O$ autor chamava a atenção para o fato de que condições de vida decentes, boas condições de trabalho, cultura física e formas de lazer e descanso são fundamentais para se promover saúde. Buss ${ }^{2}$ antecipa que as ações de promoção da saúde propriamente ditas são resultado de uma certa reação aos intensos processos de medicalização que se impunham (e ainda se impõem) à sociedade e mesmo no interior dos sistemas de saúde. Inicialmente, o termo caracterizava um nível de atenção da medicina preventiva. Porém, tal significado foi-se alterando, incorporando um sentido técnico-político envolvido no processo saúde-doença-cuidado. O termo está associado ainda, a um conjunto de valores tais como a vida, saúde, solidariedade, equidade, democracia, cidadania, desenvolvimento, participação e parceria.

Rabello ${ }^{16}$ também destaca a mudança de paradigma que o termo promoção da saúde comporta, ao questionar a hegemonia do modelo flexneriano, caracterizado pelo individualismo da especialização, tecnologização e curativismo na atenção à saúde - ainda predominantes nas práticas de saúde. A autora adverte para a dinamicidade do conceito, que deve ser elaborado continuamente a partir das demandas sociais.

Além dos aspectos biológicos e ambientais que o termo promoção da saúde sempre suscitou, há também uma vertente política, ressaltada por Winslow ${ }^{17}$, que classifica a promoção da saúde como um "esforço da comunidade organizada para alcançar políticas que melhorem as condições de saúde da população [...]”.

As seis conferências internacionais de promoção da saúde compreendidas entre 1986 e 2005 trouxeram contribuições importantes para o desenvolvimento do conceito, ampliando, ao longo de suas realizações, o escopo do termo. Se na Carta de Ottawa já se falava em promoção da saúde como um "processo de capacitação da comunidade para atuar na melhoria da sua qualidade de vida e saúde, incluindo uma maior participação no controle desse processo" ", a IV Conferência, em Jacarta, em 1997, avançou para estabelecer novos determinantes sociais da saúde, como a integração econômica global, o comércio e os meios de comunicação. Além disso, destacou a participação social, a educação e o acesso à informação como centrais para a promoção da saúde ${ }^{18}$.

Os esforços para se conceituar a promoção da saúde têm, ao mesmo tempo, o desafio de diferenciá-la da prevenção, apesar de ambos os conceitos não serem excludentes, mas complementares. Um estilo de vida saudável preconiza escolhas pessoais e a prevenção não tem como objetivo dizer o que as pessoas devem fazer mas dá opções para que tomem uma decisão informadas sobre prós e contras. A prevenção pode ser de alto risco ou de amplitude populacional. A primeira, medicalizada, é realizada quando se oferece algum tipo de tratamento para doença específica, destinando recurso diretamente a quem precisa, no modelo de cuidado individual. No caso populacional, atua-se em toda a sociedade, sem distinção entre doentes e saudáveis, independentemente do risco de cada indivíduo, em ações como a adição de flúor à água distribuída pelo governo em todas as cidades ${ }^{3}$.

Buss aponta que a promoção da saúde possui um enfoque mais amplo, cujo objetivo seria identificar e enfrentar os macrodeterminantes do processo de saúde-doença e manter um nível ótimo de vida e saúde. Já a prevenção tentaria fazer com que os indivíduos não fossem acometidos por determinadas doenças, tendo como objetivo final evitar a enfermidade. O conceito de promoção da saúde, então, antes caracterizado por um revestimento mais preventivo, hoje traz um enfoque político e técnico do processo saúde-doença-cuidado². 
Considerando-se a importância e o papel da comunicação para a promoção da saúde, cabe verificar, portanto, se após o lançamento da Política Nacional de Promoção da Saúde, o Ministério da Saúde brasileiro tem pautado sua comunicação como promotora da saúde. Para isso, foram analisadas as estratégias de comunicação direcionadas aos seguintes temas: promoção de atividade física; promoção de hábitos saudáveis de alimentação e vida; prevenção e controle do tabagismo; controle do uso abusivo de bebida alcoólica. O recorte temporal definido concentra-se nos anos de 2006 a 2013. Esses temas são parte dos prioritários elencados no documento da Política Nacional de Promoção da Saúde no Brasil ${ }^{5}$, revista em $2014^{19}$ com ampliação da abrangência de cada um deles. A pesquisa analisou também campanhas cujo tema faz referência a cuidados especiais voltados ao processo de envelhecimento, diretamente relacionado à estratégia do governo brasileiro denominada Pacto Pela Vida ${ }^{20}$. Nas últimas décadas houve um crescimento do número de idosos no país, o que fez com que o número de pessoas com mais de 60 anos no Brasil tenha superado o de países como França, Inglaterra e Itália. Essa evolução e a da expectativa de vida da população brasileira que, em 2013, chegou a 74,9 anos ${ }^{21}$ ampliaram a responsabilidade dos gestores públicos por ações de promoção da saúde voltadas para esse segmento da populaçãã22.

\section{Materiais e métodos}

Este estudo adota uma metodologia qualitativa ${ }^{23}$, com foco na interpretação da complexidade das estratégias de comunicação do Ministério da Saúde, relacionando-as, como dito anteriormente, às campanhas sobre os temas prioritários elencados na Política Nacional de Promoção da Saúde. Para analisar as estratégias de comunicação do Ministério da Saúde relacionadas às campanhas voltadas para esses temas, foi construída uma matriz de análise e, nela, cada tema é correlacionado ao ano em que foi apresentado e às estratégias de comunicação adotadas, classificando-as de acordo com seu objetivo: promotor ou preventivo, conforme esquema citado por Buss ${ }^{2}$ que organiza as características que a promoção da saúde e a prevenção de doenças assumem.

Quadro 1. Diferenças esquemáticas entre promoção e prevenção

\begin{tabular}{|l|l|l|}
\hline Categorias & Promoção da saúde & Prevenção de doenças \\
\hline Conceito de saúde & Positivo e multidimensional & Ausência de doença \\
\hline Modelo de intervenção & Participativo & Médico \\
\hline Alvo & $\begin{array}{l}\text { Toda a população, no seu ambiente } \\
\text { total }\end{array}$ & $\begin{array}{l}\text { Principalmente os grupos de alto risco da } \\
\text { população }\end{array}$ \\
\hline Incumbência & Rede de temas de saúde & Patologia específica \\
\hline Estratégias & Diversas e complementares & Geralmente única \\
\hline Abordagens & Facilitação e capacitação & Direcionadoras e persuasivas \\
\hline Direcionamento das medidas & Oferecidas à população & Impostas a grupos-alvo \\
\hline Objetivos dos programas & $\begin{array}{l}\text { Mudanças na situação dos } \\
\text { indivíduos e de seu ambiente }\end{array}$ & $\begin{array}{l}\text { Focam principalmente indivíduos e } \\
\text { grupos de pessoas }\end{array}$ \\
\hline Executores dos programas & $\begin{array}{l}\text { Organizações não-profissionais, } \\
\text { movimentos sociais, governos } \\
\text { locais, municipais, regionais e } \\
\text { nacionais etc }\end{array}$ & Profissionais da saúde \\
\hline
\end{tabular}

Fonte: Adaptado de Stachtchenko e Jenicek ${ }^{24}$.

Para objetivar a análise, este artigo se atém à análise de três das categorias que compõem o esquema Stachtchenko e Jenicek ${ }^{24}$ - alvo , abordagem e direcionamento das medidas - porque estas se aproximam mais dos aspectos comunicacionais da promoção da saúde. As demais abordadas no estudo mencionado referem-se mais a aspectos políticos do que àqueles relacionados à comunicação. Com isso, não se quer 
reduzir sua importância, mas apenas sinalizar que tais categorias estão mais vinculadas às decisões de gestores e formuladores das ações, sem, necessariamente, terem uma maior identificação com a comunicação como as aqui selecionadas. O recorte permite melhor análise sob o viés comunicacional.

A coleta de dados das campanhas do Ministério da Saúde foi realizada no endereço institucional (www.saude. gov.br) que dispõe de todo o material de campanha do órgão. Foram coletadas todas as campanhas entre os anos de 2006 e 2013. Cada um deles dava acesso às informações principais das campanhas e, em alguns casos, expunha os materiais de comunicação utilizados, desde materiais gráficos (fôlderes, cartazes, camisetas, bonés etc.) até vídeos e spots de rádio.

Embora a PNPS tenha sido lançada em 2006, não foram localizadas campanhas de nenhum dos temas elencados para análise neste trabalho no referido ano, provavelmente porque as ações podem ter sido organizadas para ter início no ano seguinte. Em 2007, não houve registro de campanhas institucionais para dois temas da PNPS: promoção de atividade física e promoção de hábitos saudáveis de alimentação e vida. A partir do levantamento dos temas, optou-se por selecionar os que apareceram com mais frequência no período investigado, quais sejam: combate ao tabagismo; promoção de hábitos saudáveis de alimentação e de vida, e cuidados especiais voltados para o processo de envelhecimento. Cada um destes apareceu em cinco dos oito anos que compõem a amostra. Promoção da atividade física e controle do uso abusivo de bebida alcoólica apareceram com menor frequência, três vezes cada, e portanto, serão abordados em pesquisa futura.

\section{Resultados e discussão}

A amostra compreendeu 14 campanhas promovidas pelo Ministério da Saúde brasileiro e, como mencionado anteriormente, selecionou três temas prioritários: combate ao tabagismo; promoção de hábitos saudáveis de alimentação e de vida, e cuidados especiais voltados para o processo de envelhecimento. Na categoria "direcionamento das medidas", das 14 ações analisadas, apenas três foram classificadas como "oferecidas à população", ou seja, com um caráter mais amplo e mais condizente com estratégias de promoção ${ }^{18}$. Foram elas: o Dia da promoção da qualidade de vida, em 2010; a campanha Pequenos cuidados: uma grande proteção, em 2013 (ambas sobre promoção de hábitos saudáveis de alimentação e de vida); e a campanha Viver bem é viver com saúde (sobre o tema combate ao tabagismo), em 2011. As demais foram classificadas como "impostas a grupos-alvo", ou seja, de caráter mais preventivo. Com a categoria "alvo", chegou-se à mesma conclusão, tendo sido apenas três das 14 ações classificadas como destinadas a "toda a população, no seu ambiente". Essas exceções foram as mesmas verificadas quanto à categoria anterior, "direcionamento das medidas". No que diz respeito à categoria "abordagens", as ações selecionadas foram classificadas como "direcionadoras e persuasivas", uma vez que, além de se dirigirem a públicos específicos, buscam, por meio de suas estratégias de comunicação, persuadilos a medidas referentes a um tema também específico. Além dessas evidências, os textos das campanhas de comunicação analisados deixam claro, na maioria das vezes, de que se referem a ações voltadas ou para públicos específicos ou à prevenção de doenças.

Observando especificamente cada tema, temos que para o combate ao tabagismo, a comunicação estava com abordagem direcionadora e persuasiva, focada em públicos específicos como "adolescentes", "fumantes de narguilé", "pessoas entre 25 e 40 anos", ou, simplesmente, "fumantes", com exceção do ano de 2011, conforme consta no Quadro 2. É importante observar que, mesmo com a pretensão de se reduzir o hábito de fumar, uma comunicação de fato promotora deveria estender-se mesmo aos grupos de não usuários de tabaco, uma vez que podem vir a sê-lo. 
Quadro 2. Síntese analítica das campanhas de combate ao tabagismo (2006-2013)

\begin{tabular}{|c|c|c|c|c|}
\hline Ano & Alvo & Abordagens & $\begin{array}{l}\text { Direcionamento de } \\
\text { medidas }\end{array}$ & Observação/texto da campanha \\
\hline 2007 & $\begin{array}{l}\text { Pessoas de } \\
\text { ambos os sexos, } \\
\text { entre } 25 \text { e } 40 \\
\text { anos, das classes } \\
A, B, C, D, E\end{array}$ & $\begin{array}{l}\text { Direcionadoras e } \\
\text { persuasivas }\end{array}$ & Imposta a grupos-alvo & $\begin{array}{l}\text { "Deixe seu coração sempre em festa. } \\
\text { Pratique saúde. Não abuse do álcool } \\
\text { e, se beber, não dirija. Fique longe } \\
\text { das drogas e não fume." }\end{array}$ \\
\hline 2008 & Adolescentes & $\begin{array}{l}\text { Direcionadoras e } \\
\text { persuasivas }\end{array}$ & Imposta a grupos-alvo & $\begin{array}{l}\text { "Fique Esperto, começar a fumar é } \\
\text { cair na deles". }\end{array}$ \\
\hline 2009 & Fumantes & $\begin{array}{l}\text { Direcionadoras e } \\
\text { persuasivas }\end{array}$ & Imposta a grupos-alvo & "Deixar de fumar é a saída". \\
\hline 2011 & $\begin{array}{l}\text { Toda a } \\
\text { população, no } \\
\text { seu ambiente }\end{array}$ & $\begin{array}{l}\text { Direcionadoras e } \\
\text { persuasivas }\end{array}$ & Oferecidas à população & $\begin{array}{l}\text { "Viver bem é viver com saúde. Fique } \\
\text { longe do cigarro". Uso de imagem de } \\
\text { dois casais de jovens (um casal negro } \\
\text { e outro branco) }\end{array}$ \\
\hline 2013 & $\begin{array}{l}\text { Usuários de } \\
\text { narguilé }\end{array}$ & $\begin{array}{l}\text { Direcionadoras e } \\
\text { persuasivas }\end{array}$ & Imposta a grupos-alvo & $\begin{array}{l}\text { "Parece inofensivo, mas fumar } \\
\text { narguilé é como fumar } 100 \text { cigarros". }\end{array}$ \\
\hline
\end{tabular}

Fonte: Elaborado pelos autores a partir das campanhas dispostas no site do Ministério da Saúde no período abrangido por este estudo (2006-2013).

Em relação à promoção de hábitos saudáveis de alimentação e vida, dos quatro anos em que campanhas sobre o tema foram realizadas, a metade era direcionadora e persuasiva e voltada a públicos específicos: "mães" e "mães lactantes". Nos dois anos seguintes, verifica-se uma possível mudança de postura, passando o alvo a ser "toda a população em seu ambiente total" conforme consta no Quadro 3.

Quadro 3. Síntese analítica das campanhas sobre hábitos saudáveis de alimentação (2006-2013)

\begin{tabular}{|c|c|c|c|c|}
\hline Ano & Alvo & Abordagens & $\begin{array}{c}\text { Direcionamento de } \\
\text { medidas }\end{array}$ & $\begin{array}{l}\text { Observação/texto da } \\
\text { campanha }\end{array}$ \\
\hline 2008 & Mães & $\begin{array}{l}\text { Direcionadoras e } \\
\text { persuasivas }\end{array}$ & Imposta a grupos-alvo & $\begin{array}{l}\text { "Nada mais natural que } \\
\text { amamentar. Nada mais importante } \\
\text { que apoiar". }\end{array}$ \\
\hline 2009 & $\begin{array}{l}\text { Mães e } \\
\text { lactantes }\end{array}$ & $\begin{array}{l}\text { Direcionadoras e } \\
\text { persuasivas }\end{array}$ & Imposta a grupos-alvo & $\begin{array}{l}\text { "Para você é leite. Para a criança, } \\
\text { é vida". Imagem de uma mãe } \\
\text { (atriz da Globo) dando de mamar. }\end{array}$ \\
\hline 2010 & $\begin{array}{l}\text { Toda a } \\
\text { população, no } \\
\text { seu ambiente }\end{array}$ & $\begin{array}{l}\text { Direcionadoras e } \\
\text { persuasivas }\end{array}$ & Oferecidas à população & $\begin{array}{l}\text { Dia da Promoção da Qualidade de } \\
\text { Vida. Campanha estimula uso de } \\
\text { transportes alternativos, práticas } \\
\text { de atividades esportivas e outros } \\
\text { hábitos saudáveis. }\end{array}$ \\
\hline 2013 & $\begin{array}{l}\text { Toda a } \\
\text { população, no } \\
\text { seu ambiente } \\
\text { total }\end{array}$ & $\begin{array}{l}\text { Direcionadoras e } \\
\text { persuasivas }\end{array}$ & Oferecidas à população & $\begin{array}{l}\text { Campanha estimula hábitos } \\
\text { saudáveis, mas foca na questão } \\
\text { do uso correto da água. } \\
\text { "Pequenos cuidados: uma grande } \\
\text { proteção". }\end{array}$ \\
\hline
\end{tabular}

Fonte: Elaborado pelos autores a partir das campanhas dispostas no site do Ministério da Saúde no período abrangido por este estudo (2006-2013). 
De todas as campanhas analisadas, aquelas voltadas ao processo de envelhecimento foram as que mantiveram, em todos os períodos estudados, o foco em grupos específicos. Com exceção do ano de 2011, quando as crianças foram o alvo da campanha - para se estimular hábitos saudáveis visando minimizar os riscos de osteoporose na vida adulta -, em todos os demais anos as campanhas tiveram por foco a população acima de 60 anos.

Em grande parte isso pode ser explicado pelo fato de as campanhas terem por tema a vacinação contra a gripe, destinadas a esse grupo específico. Mesmo quando o grupo trabalhado foi outro (crianças), o objetivo da campanha era também bastante específico - minimizar riscos de osteoporose.

Reitera-se que tais advertências e estratégias não estão sendo julgadas quanto a seus méritos, uma vez que as medidas propostas são legitimas e necessárias. Porém, tendo em vista as recentes mudanças no perfil etário da população brasileira, que vem sistematicamente ampliando sua longevidade, campanhas de promoção abordariam, também, a qualidade de vida que se busca atingir, visando, para isso, a toda a população, e não apenas públicos específicos.

Quadro 4. Síntese analítica das campanhas sobre processo de envelhecimento (2006-2013)

\begin{tabular}{|c|c|c|c|c|}
\hline Ano & Alvo & Abordagens & $\begin{array}{l}\text { Direcionamento de } \\
\text { medidas }\end{array}$ & $\begin{array}{l}\text { Observação/texto da } \\
\text { campanha }\end{array}$ \\
\hline 2007 & $\begin{array}{l}\text { Pessoas com } \\
60 \text { anos ou } \\
\text { mais }\end{array}$ & $\begin{array}{l}\text { Direcionadoras e } \\
\text { persuasivas }\end{array}$ & Imposta a grupos-alvo & $\begin{array}{l}\text { Campanha Nacional de } \\
\text { Vacinação do Idoso. Slogan: } \\
\text { "Fique ativo. Vacine-se contra } \\
\text { a gripe". }\end{array}$ \\
\hline 2008 & $\begin{array}{l}\text { Pessoas com } \\
60 \text { anos ou } \\
\text { mais }\end{array}$ & $\begin{array}{l}\text { Direcionadoras e } \\
\text { persuasivas }\end{array}$ & Imposta a grupos-alvo & $\begin{array}{l}\text { "Não deixe a gripe derrubar } \\
\text { você! Vacine-se." }\end{array}$ \\
\hline 2009 & $\begin{array}{l}\text { Pessoas com } \\
60 \text { anos ou } \\
\text { mais }\end{array}$ & $\begin{array}{l}\text { Direcionadoras e } \\
\text { persuasivas }\end{array}$ & Imposta a grupos-alvo & $\begin{array}{l}\text { "Deixe a gripe na saudade e } \\
\text { marque um encontro com os } \\
\text { amigos. Vacine-se." }\end{array}$ \\
\hline 2010 & $\begin{array}{l}\text { Pessoas com } \\
60 \text { anos ou } \\
\text { mais }\end{array}$ & $\begin{array}{l}\text { Direcionadoras e } \\
\text { persuasivas }\end{array}$ & Imposta a grupos-alvo & $\begin{array}{l}\text { "Influenza. Quanto mais } \\
\text { prevenção mais proteção". }\end{array}$ \\
\hline 2011 & Criança & $\begin{array}{l}\text { Direcionadoras e } \\
\text { persuasivas }\end{array}$ & Imposta a grupos-alvo & $\begin{array}{l}\text { Campanha estimula adoção } \\
\text { de hábitos saudáveis } \\
\text { pelas crianças para evitar } \\
\text { ou minimizar riscos de } \\
\text { osteoporose na vida adulta. } \\
\text { "Prevenção da osteoporose: } \\
\text { da criança à pessoa idosa". }\end{array}$ \\
\hline
\end{tabular}

Fonte: Elaborado pelos autores a partir das campanhas dispostas no site do Ministério da Saúde no período abrangido por este estudo (2006-2013).

Além dessas evidências, os textos das campanhas de comunicação analisados deixam claro, na maioria das vezes, que se referem a ações voltadas ou a públicos específicos ou à prevenção de doenças.

É possível afirmar que essas observações ilustram as imprecisões conceituais entre prevenção e promoção da saúde. De acordo com Buss "boa parte da confusão entre promoção e prevenção advém da grande ênfase em modificações de comportamento individual e do foco quase exclusivo na redução de fatores de risco para determinadas doenças, vigentes em certos programas intitulados de promoção da saúde [...]”. 
O que se infere das análises realizadas é que as campanhas de comunicação executadas pelo Ministério da Saúde no período avaliado estavam mais voltadas para a prevenção do que para a promoção, ainda que fossem relacionadas a temas da Política Nacional de Promoção da Saúde. Um dos pilares da promoção da saúde é a intersetorialidade, na medida em que pressupõe articulação de saberes em construção coletiva com base em diferentes lugares, culturas institucionais e linguagens ${ }^{23,25}$. Possivelmente, no processo de elaboração das ações comunicativas do Ministério da Saúde, haja ausência de intersetorialidade e, por isso, as campanhas se atêm à prevenção de riscos específicos.

\section{Conclusão}

Mesmo no ambiente institucional da saúde pública brasileira ainda persistem confusões conceituais entre prevenção e promoção da saúde, que repercutem na comunicação institucional do Ministério da Saúde, cujas estratégias assumem características mais preventivas do que promotoras da saúde; quando se analisam os públicos-alvo, as abordagens nas campanhas revelam a especificidade de cada uma delas. Por um lado, seria possível dizer que essas medidas sintonizam-se com teorias da comunicação segundo as quais a heterogeneidade da população demanda estratégias correspondentes às características dos seus mais diversos grupos sociais ${ }^{26-28}$. Porém, a inclusão de alguns e exclusão dos demais nos temas das campanhas não corresponderia a uma linha de ação promotora da saúde, mas, sim, preventiva.

Não se pode prescindir da comunicação para a promoção da saúde, uma vez que ela é essencial para atingir seus objetivos, e deve ser considerada no campo das formulações das estratégias de promoção.

Tal percepção em nada questiona os objetivos, intenção ou qualidade das campanhas empreendidas pelo Ministério da Saúde. Apenas lança luz sobre a permanência de um certo distanciamento, ou mesmo confusões conceituais, quando se trata do tema 'promoção da saúde'. Portanto, faz-se necessário repensar as estratégias de comunicação adotadas para os temas das campanhas financiadas com recursos públicos de modo que a promoção da saúde seja efetivamente tratada como tal, permitindo, com isso, assegurar a qualidade de vida da população e a melhoria dos indicadores da saúde pública brasileira.

\section{Referências}

1. Canadá. Carta de Ottawa. Primeira Conferência Internacional sobre Promoção da Saúde. Ottawa, 1986. [acesso em 10 jul 2015]. Disponível em http://bvsms.saude.gov.br/bvs/publicacoes/cartas promocao.pdf

2. Buss PM. Uma introdução ao conceito de promoção da saúde. In: Czeresnia D, Freitas CM, organizadores. Promoção da saúde: conceitos, reflexões, tendências. 2 ed. Rio de Janeiro:Fiocruz; 2012. p. $19-42$.

3. Rose G. Estratégias da medicina preventiva. Porto Alegre: Artmed; 2010.

4. Czeresnia D. Conceito de saúde e a diferença entre prevenção e promoção. In: Czeresnia D; Freitas CM, organizadores. Promoção da saúde: conceitos, reflexões, tendências. 2 ed. Rio de Janeiro: Fiocruz; 2012. p. 43-57.

5. Brasil. Ministério da Saúde. Secretaria de Vigilância em Saúde. Departamento de Análise de Situação e Saúde . Política nacional de promoção da saúde. Brasília; 2006. (Textos básicos de saúde, série B).

6. Chauí M. Cultura e democracia: o discurso competente e outras falas. 12 ed. São Paulo: Cortez; 2007.

7. Fonseca A. A evolução histórica das políticas sociais no Brasil. In: Canela G, organizador. Políticas públicas sociais e os desafios para o jornalismo. São Paulo: Cortez; 2008.

8. Araújo I, Cardoso JM. Comunicação e saúde. Rio de Janeiro: Fiocruz; 2007.

9. Habermas J. Mudança estrutural da esfera pública. 2 ed. Rio de Janeiro: Tempo Brasileiro; 2003.

10. Hansen JH. Como entender a saúde na comunicação? São Paulo: Paulus; 2004. 
11. Morin E. Desafios da transdiciplinaridade e da complexidade. In: Audy JLN, Morosini MC. Inovação e interdisciplinaridade na universidade, organizadores. Porto Alegre: Edipucrs; 2007. p. 22-31.

12. Fausto-Neto A. Percepções acerca dos campos da saúde e da comunicação. In: Pitta AMR, organizador. Saúde e comunicação: visibilidades e silêncios. São Paulo: Hucitec; 1995. p. 267-93

13. Araujo I. Pesquisa em Comunicação e saúde: um cenário desenhado nos grupos de trabalho em congressos. In: Pessoni A, organizador. Comunicação, saúde e pluralidade: novos olhares e abordagens em pauta. São Caetano do Sul: USCS; 2015. p. 121-143. (Comunicação \& Inovação, v. 6).

14. Lee RG, Garvin T. Moving from information transfer to information exchange in health and health care. Soc. Sci. Med. 2003 Feb;56(3):449-64.

15. Sigerist $\mathrm{H}$. The social sciences in the medical school. In: crossroads. New York: Henry Schumann Publisher; 1946. , organizer. The university at the

16. Rabello LS. Promoção da saúde: a construção social de um conceito em perspectiva comparada. Rio de Janeiro: Fiocruz, 2013.

17. Winslow CE. The untilled fields of public health. Science. 1920 Jan 9;51(1306):23-33.

18. Brasil. Ministério da Saúde. Secretaria de Políticas de Saúde. Projeto Promoção da Saúde. As cartas da promoção da saúde. Brasília (DF); 2002. (Textos básicos em saúde, série B).

19. Brasil. Ministério da Saúde. Portaria no 2.446, de 11 de novembro de 2014. Redefine a Política Nacional de Promoção da Saúde (PNPS). Diário Oficial da União, Brasília (DF), 2014 nov 12. Seção 1, n. 63, p. 138 [acesso em 10 dez 2014]. Disponível em http://bvsms.saude.gov.br/bvs/saudelegis/gm/2014/ prt2446 $11 \quad 11$ 2014.html

20. Ministério da Saúde. Secretaria Executiva. Departamento de Apoio à Descentralização. CoordenaçãoGeral de Apoio à Gestão Descentralizada. Diretrizes operacionais dos Pactos pela Vida, em Defesa do SUS e de Gestão. Brasília (DF), 2006 [citado em 2015 fev 14]. (Normas e Manuais Técnicos, A). Disponível em: http://www.saude.mppr.mp.br/arquivos/File/volume1.pdf

21. IBGE. Tábua completa de mortalidade: ambos os sexos: 2012. Rio de Janeiro, 2013 [citado em 2015 fev 21]. Disponível em: http://www.ibge.gov.br/home/estatistica/populacao/tabuadevida/2012/

22. Minayo MCS. O envelhecimento da população brasileira e os desafios para o setor saúde. Cad. Saúde Pública. 2012 Feb;28(2):208-210.

23. Creswell JW. Projeto de pesquisa: métodos qualitativo, quantitativo e misto. 3 ed. Porto Alegre: Artmed; 2012.

24. Stachtchenko S, Jenicek M. Conceptual differences between prevention and health promotion: research implications for community health programs. Can J Public Health 1990 Jan-Feb;81(1):53-9

25. Sícoli JL, Nascimento PR. Health promotion: concepts, principles and practice. Interface. 2003 Feb;7(12):101-122

26. Kusma SZ, Moysés ST, Moysés SJ. Promoção da saúde: perspectivas avaliativas para a saúde bucal na atenção primária em saúde. Cad. Saúde Pública [Internet]. 2012 28(Suppl):s9-19 [citado em 2015 jun 23]. Disponível em: http://www.scielo.br/scielo.php?script=sci arttext\&pid=S0102$\underline{311 \times 2012001300003 \& \operatorname{lng}=e n}$

27. Polistchuck I, Trinta AR. Teorias da comunicação: o pensamento e a prática da comunicação social. Rio de Janeiro: Campus; 2003.

28. Duarte M. Comunicação e cidadania. In: Duarte J, organizador. Comunicação pública: Estado, governo, mercado, sociedade e interesse público. São Paulo: Atlas; 2007. p. 95-115. 